\title{
NOGUERA, María. Los cuentos de Miguel Torga. Historias de un reino maravilloso. Salamanca: Luso-Española, 2012. 234 p.
}

Durante muitos anos, parte da intelectualidade portuguesa esperava que Miguel Torga recebesse o mais ambicionado dos prêmios literários: o Nobel. Diversos amigos, entre escritores e jornalistas, incendiaram suas relações em busca de assinaturas para amparar a candidatura de Torga. Há, inclusive, uma carta de Sophia de Mello Breyner Andresen, datada de 1959, pedindo o apoio a Jorge de Sena, ao mesmo tempo em que a poeta reclama de muitos de seus conterrâneos por absterem-se dessa indicação.

Miguel Torga era este indivíduo polêmico, capaz de irradiar amores e ódios. Ele mesmo proclamou-se, na sua escrita diarística, uma pessoa de difícil convivência. Contudo, o seu talento, especialmente como contista, é uma unanimidade. E é voltado para este gênero que se debruça a docente da Universidad de Navarra, María Noguera, com o livro Los cuentos de Miguel Torga. Historias de um reino maravilloso.

Obra de fôlego, María Noguera acompanha as cinco antologias de contos de Miguel Torga (em onze anos de profícua criação, são publicados Bichos, Contos da montanha, Rua, Novos contos da montanha e Pedras lavradas), não sem antes perpassar brevemente por sua vida e pelo contexto histórico de sua produção, uma vez que "la experiencia dolorosa de ese tiempo favoreció en él la reflexión acerca del valor del arte y de la literatura frente al sufrimiento humano; también el interés por algunos temas como la libertad, la soledad, el sometimiento y la dominación entre los hombres" (NOGUERA, 2012, p. 14) ${ }^{1}$. Contudo, Noguera sublinha que não pretende traçar paralelos entre vida e obra, tampouco afirmar que o texto torguiano seja consequência direta do período histórico em que ele viveu, trazendo como suporte a própria fala do autor quando, em seu diário, citando Beethoven, disse que o verdadeiro artista cria também

\footnotetext{
1 As passagens retiradas da obra de María Noguera, a partir de agora, serão referenciadas apenas com o número da página.

2 'Los censores también se encargabam de controlar la publicación de nuevos libros, tanto portugueses como extranjeros. Como en el caso de Torga com "El cuarto día" de La creación del mundo en 1939, Cuentos de la montaña en 1941 y Sinfonía en 1947 [...]' (41).
}

as condições para sua obra existir. Fugindo de uma lógica reducionista, biografista, portanto, que explicaria a literatura de Torga a partir de uma vivência cercada por uma ditadura repressora, que tantas vezes, aliás, censurou a obra do autor ${ }^{2}$, Noguera constroi uma consistente recuperação deste período histórico, deixando ao leitor a tarefa de fazer, se assim o entender, essas conexões.

O acerto no capítulo histórico vem do entrelaçamento entre a produção de Miguel Torga e o mundo ao redor dele: "Em 1925, cuando Torga volvió de Brasil y desembarcó com su tio en Oporto, el sistema republicano estaba sumido en una gran crisis política y financiera" (34). Noguera escapa de uma construção sem vigor, fria, que poderia tornar-se um apêndice, um desvio do núcleo de seu debate, para apresentar uma História (em maiúsculo) que envolve (ou engole?) a história do autor: "Quando publicou Bichos em 1940, el salazarismo llevaba vigente de forma oficial en el país siete años, desde que en 1933 se dio por terminado el periodo de formación de los órganos administrativos, las instituciones y el soporte legal del llamado Estado Novo" (33). Assim, ao mesmo tempo em que testemunha a trajetória de Torga entre os anos 20 e 70, o leitor acompanha um período político de sombras em Portugal. A autora igualmente traça paralelos entre o salazarismo português e a Guerra Civil espanhola. Segundo Noguera, Portugal foi um dos mais fortes centros de conspiração antirrepublicana na Europa, e a Guerra Civil espanhola auxiliou para que Salazar consolidasse seu posto no contexto internacional: "Desde que la República se instauró en España en 1931, la situación de nuestro país preocupó mucho a Salazar, quien pensaba que podía 'contagiar' a Portugal. Por eso, el levantamiento militar de julio de 1936 fue muy bien acogido por el gobierno portugués" (42). Percorrendo a História portuguesa até a mítica queda (da cadeira e do poder) de Salazar, em 1968, a autora traz as palavras de Miguel Torga, extraídas de seus diários, para ilustrar e referendar o período sob a sua própria ótica. Igualmente, Noguera resgata o contexto e as escolas literárias da época (Presença e Neorrealismo) e a não filiação de Torga a nenhuma delas: "Se tuvo 
siempre a sí mismo como un desterrado, como un escritor huérfano dentro del escenario contemporáneo de las letras lusas, lo que le llevó a denunciar la falta de originalidad y la mediocridad de la mayoría de sus coetáneos" (50).

María Noguera afirma que a resposta de Miguel Torga às constantes censuras e perseguições políticas sofridas, que inclusive levaram-no à prisão, foi nunca ter deixado de escrever: "Seguir publicando sus libros a pesar de las dificuldades se convirtió para él en el modo mais eficaz de enfrentarse el régimen" (64). Graças a sua bem-sucedida carreira médica, o escritor pode bancar a publicação de seus livros e, em pouco mais de uma década, entre 1940 e 1951, lançou cinco importantes obras, solidificando sua contística como uma das mais notáveis em língua portuguesa do século XX. Projeto de todo uma vida, o autor continuou burilando seu texto, em subsequentes reedições, nas quais trazia à cena pequenas correções, exclusões, prólogos e até alterações na estrutura e na ordem dos contos nos livros.

O terceiro capítulo de Los cuentos de Miguel Torga. Historias de un reino maravilloso é o núcleo da obra. "Cinco libros de cuentos y casi cien relatos" apresenta, de forma cronológica, as cinco antologias de Miguel Torga por María Noguera investigadas.

Bichos, de 1940, como o próprio título já alude, traz como protagonistas animais como o corvo, o gato, o sapo, o galo, o touro, entre outros. Noguera sublinha a proximidade desses bichos com o universo agrário, tão caro ao escritor, que seria explorado de forma ainda mais contundente nas obras seguintes: "Si bien desde un ponto de vista extraliterario podría decirse que Bichos es un libro de corte fantástico - se les atribuye a los animales la capacidad de razonar, sentir o hablar -, en sus historias no prevalece lo imposible, lo maravilloso o lo insólito, sino más bien una serie de acontecimientos, hechos y acciones que podrían considerarse ordinarios" (74). É o sabor campesino que habita o montanhoso norte português, cenário de tantas histórias torguianas. São bichos que vivem soltos na natureza, ou, muitas vezes, agem como se homens fossem. Noguera aproxima e distancia homem e bicho para afirmar que esta obra apresenta uma temática recorrente na literatura de Torga: a humanização do animal e a animalização do homem. Além disso, a autora aponta a relação dos títulos dos contos com o comportamento dos personagens ("Mago", "Ladino", "Morgado", entre outros) ou com a tradição cultural do Ocidente ("Nero", "Madalena", Jesus", entre outros), configurando a todos "experiencias vitales relacionadas com la deformación o la soledad. Tengam o no rasgos humanos, son personajes que sufren o bien la parálisis de algún miembro del cuerpo [...] o bien el aislamiento, el encierro, la clausura, la orfandad y el exilio" (94).
A incisiva análise dos vinte e três textos de Contos da montanha ${ }^{3}$ (publicado em 1941), todos eles ambientados na região norte portuguesa, dá-se a partir de uma perspectiva que, obviamente, perpassa a geografia do espaço, que faz destes personagens simples, pobres e sem grandes expectativas seres ambíguos, que carregam suas dores, seus amores, suas forças e suas fraquezas, seu lado puro e até mesmo seus instintos mais selvagens. O exame dos textos de Torga, por Noguera, é sempre comparativo. Seja aproximando personagens de diferentes contos, seja agrupando aldeias que apresentam sua própria geografia humana, a autora acaba por desenvolver uma rica cartografia desses seres de papel, que constituem um microcosmo altamente significativo e representativo deste Portugal esquecido:

Los relatos de Cuentos de la montaña narran historias cuyos protagonistas tratan de salir adelante en la adversidad, cayendo unas veces en la desesperación, resignandose otras, y recurriendo en algunos casos a la satisfacción de los impulsos más bajos, al robo, al adulterio, la mentira e incluso el asesinato. En la frustración en la que a menudo se ven inmersos, la creación artística en general y la literatura en concreto les sirve en ocasiones de consuelo o alivio. (118)

Em 1944, Miguel Torga publicou Novos contos da montanha. María Noguera chama a atenção para um importante detalhe: a função desse adjetivo novos no título ter relação com o fato de a obra 'original' estar confiscada pela PIDE. São vinte e duas histórias em que, segundo a autora, e repetindo o estudioso Francisco Cota Fagundes, a montanha emerge como forma e como ideia. São diferentes personagens no mesmo ambiente agrário, de isolamento e analfabetismo, de Contos da montanha. Noguera opera uma espécie de divisão dos personagens de acordo com sua faixa-etária, e constrói sua análise a partir de quatro importantes características, que percorrem suas distintas fases da vida, da velhice ao nascimento: 1) a decrepitude; 2) a aproximação dos personagens adultos a forças da natureza ou a seres do reino animal; 3) o despertar e a frustração da sexualidade na adolescência; e 4) o caráter enigmático de algumas crianças e recém-nascidos. Outra vez, a investigação da autora parte da aproximação entre os personagens, que podem ser examinados a partir desses subgrupos por ela criados, em função de sua perspectiva de vida. Estes, entretanto, são rearranjados, quando Noguera observa conflitos de interesse entre os de uma mesma geração, e também entre personagens de diferentes gerações.

\footnotetext{
3 Segundo a autora, a obra - que tinha como título original Montanhafoi censurada e proibida pela ditadura salazarista. Alguns exemplares, contudo, circulavam de forma clandestina, vindo desde o Rio de Janeiro. Somente no final dos anos 1960 o livro seria liberado.
} 
Rua foi publicado em 1942 e, como grande diferencial, tem seus relatos ambientados em um espaço urbano. Noguera salienta que os treze contos do livro, ainda que tragam um contexto urbano impreciso e indefinido, desenvolvem-se, em sua maioria, em pequenas cidades desconhecidas, um meio termo entre as aldeias da serra e os grandes centros urbanos, como Lisboa ou Porto, que sintetizam a vida comezinha lusitana: "Ninguna alude a una localidad em concreto; por otro, nada hace sospechar que todas tengan lugar en un mismo núcleo urbano. De una u otra forma, lo que sí parece evidente es que la ciudad es un territorio poco explorado en la cuentística torguiana que emerge - precisamente - cuando Torga se establece en Coimbra" (134). A autora pressupõe que a criação desta obra tenha se dado quando o autor viveu em Coimbra, mas essa informação torna-se irrelevante, pois em nada altera ou influencia a leitura dos textos. Como em suas análises de Novos contos da montanha, Noguera vê em Rua um abismo geracional entre os personagens, especialmente em relações pai-filho desagregadas, reforçando essa como uma forte característica do autor em sua contística.

Apesar de ser uma obra ambientada num espaço urbano, a serra também mostra-se aqui presente. É identificável a existência da montanha na cidade; ou, ao menos, a presença de homens da montanha que, em busca de uma vida melhor, abandonam suas aldeias e partem para o mundo urbano. O êxodo rural, a desertificação do mundo agrário, a busca pelo prestígio social são alguns dos temas apontados por Noguera como preponderantes nesta obra. A autora percorre essas cidades e assinala que a capital portuguesa aparece como um espaço quase inatingível, porque distante, tanto geograficamente quanto economicamente, uma vez que as montanhas e a precariedade da vida nas pequenas cidades do interior português inviabilizariam a chegada a Lisboa. E, por sua vez, Lisboa é a porta de saída para o mundo "civilizado", uma saída possível em busca de um futuro mais próspero. Mais uma vez, Noguera detém-se a uma análise quase cartográfica, percorrendo com o dedo o mapa geográfico dos contos, do macro ao microcosmo: as cidades, as ruas, as casas e os lugares de trabalho e, finalmente, elementos fora da cidade, como bosques e rios. A partir deste passeio pelas ruas em que habitam os personagens de Torga, através de um olhar microscópico, a autora vai esquadrinhando esses seres, muitas vezes, abandonados à própria sorte. Sua última perspectiva interpretativa leva o nome de "Movimento e paralisia" e mostra que: "las características del espacio urbano de Rúa propician o bien el desplazamiento o bien el estatismo de sus protagonistas, pues se mueven o se detienen según se hallen en la calle, en las casas o a las afueras de la ciudad. Tanto es así que podrían dividirse en personajes dinámicos y estáticos" (156). Noguera salienta, ainda, que, a confirmar sua tese, o início e o final dos contos, quase sempre, trazem imagens reveladoras de algum tipo de mobilidade ou de paralisia.

Por fim, a autora relê a obra Pedras lavradas, de 1951, em que surge uma mistura do mundo agrário e do urbano. Na última obra analisada, María Noguera parte para uma curiosa leitura a partir do reino mineral, desenvolvendo seus argumentos em função desses personagens, muitas vezes seres erosivos, ou ressecados tal qual a terra que habitam. Não apenas os personagens, diz Noguera, mas também as relações interpessoais que mantêm muitas vezes são representativas desse espaço geológico, quase sempre quebradiço, esfarelado, árido. O grande agente corrosivo, sugere a autora, assim como na natureza, é o tempo: "El transcurrir de las horas, los días, los meses, las estaciones y los años se entiende como un agente erosivo que provoca el marchitar de las flores, el envejecimiento de las personas, la apatía y el desamor, entre otras consecuencias negativas" (193). É o tempo que tudo destrói, nesta e noutras histórias.

As cinco obras de contos de Miguel Torga são esmiuçadas com profundidade por María Noguera. Talvez a única crítica a este capítulo central seja a configuração um pouco tradicional com que os livros são analisados: o modo cronológico cristaliza as obras, apresentando-as como se estanques. Tendo em vista a junção de enredos, personagens e universos elaborada pela autora dentro de cada subcapítulo, na análise de cada um dos livros, uma imbricação dessas obras, apontando as semelhanças e diferenças entre elas, resultaria uma leitura ainda mais potencializada. Ao menos, Contos da montanha e Novos contos da montanha poderiam figurar num mesmo subcapítulo, em vez da distância em função da preferência pela ordem cronológica, especialmente por conta da extrema familiaridade dessas obras gêmeas, como o próprio Torga as definiu. Contudo, esse detalhe formal em nada desmerece o apuro da leitura de María Noguera que, no capítulo final, de certa forma, opera neste sentido e presenteia o leitor com uma espécie de mapa temático de todos os contos de Miguel Torga. Aqui, sim, temos todo o universo dos contos reunidos e divididos em grandes constelações: a relação do homem com o reino animal e vegetal, com o espaço físico, com a norma e com o mistério.

Miguel Torga, em seus textos, borra o tempo histórico. Nós, leitores, mergulhamos na atmosfera da montanha e despimo-nos das convenções sociais da contemporaneidade. O sabor mítico desse tempo-espaço produz uma sensação hipnótica na leitura. Também nós estamos lá, convivendo com Maria Lionça, Vicente, Julião, Lídia, pastor Gabriel, arrancados que somos de nossos ruídos citadinos e reconfigurados no silêncio 
serrano, onde podemos distinguir o som do vento na copa das árvores, o cantar do pássaro, o latir do cão. Talvez até consigamos ouvir os cascos do macho que leva o médico, este autor que construiu um painel de seres esquecidos numa região esquecida de um país que enfrenta o esquecimento junto ao resto do mundo. Seres esquecidos que, pelo poder da palavra, atingem o protagonismo, anunciam-se. Uma gente simples que María Noguera recupera com rara minúcia em uma obra fundamental não só para os estudiosos da literatura, mas especialmente para os amantes dos bons enredos, aqueles que ainda se emocionam com a capacidade que um excelente contador de histórias tem para nos transportar a outros universos. Nesse sentido, Los cuentos de Miguel Torga. Historias de un reino maravilloso é um saboroso convite para outra vez mergulharmos nos pequenos relatos desse notável escritor.

PAULO RiCARDO KRALIK ANGELINI PUCRS

Recebido: 21 de fevereiro 2014 Aprovado: 29 de maio 2014 Contato: paulokralik@gmail.com 